\title{
Uso das Mídias Sociais nas Eleições e seu Impacto nos Eleitores: um estudo
}

\section{bibliométrico}

\author{
Use of Social Media in Elections and its Impact on Voters: a bibliometric study \\ Davi Pinheiro Santana*1, Jefferson David Araujo Sales ${ }^{1}$, Alessandra Cabral Nogueira Lima ${ }^{1}$ \\ ${ }^{1}$ Universidade Federal de Sergipe, Sergipe, Brasil.
}

\begin{tabular}{|c|c|}
\hline INFO A RTIGO & RES U MO \\
\hline $\begin{array}{l}\text { Palavras-chave: } \\
\text { Mídias Sociais, } \\
\text { Política, } \\
\text { Eleições, } \\
\text { Eleitores, } \\
\text { Bibliometria. }\end{array}$ & $\begin{array}{l}\text { Com o crescente uso das aplicações tecnológicas, os artefatos e ferramentas } \\
\text { ganharam importância significativa, dentre eles as mídias sociais. No campo } \\
\text { da política não é diferente, já que após as eleições americanas de } 2008 \text {, o uso } \\
\text { dessas ferramentas tornou-se crucial em campanhas. A atenção voltou-se para } \\
\text { esse tema de estudo, contudo, investigam como os políticos as utilizavam, seja } \\
\text { para mobilizar eleitores, gerar mais participação e/ou engajamento. Em } \\
\text { complemento a isso, pesquisadores do campo afirmam que pesquisas recentes } \\
\text { focaram apenas para o contexto dos agentes políticos, preterindo a realidade } \\
\text { dos eleitores. Perante esse movimento encontrado na literatura, este estudo } \\
\text { teve como objetivo apresentar e discutir a produção científica, durante o } \\
\text { período de } 2008 \text { a } 2020 \text {, sobre os temas: mídias sociais, eleições e eleitores. } \\
\text { O diagnóstico/levantamento aponta para uma diferença no número de } \\
\text { pesquisas realizadas entre os cenários, como também, indica diferentes } \\
\text { caminhos para que sejam desenvolvidas investigações no contexto dos } \\
\text { eleitores. }\end{array}$ \\
\hline ARTICLE INFO & A B S T R A C T \\
\hline $\begin{array}{l}\text { Keywords: } \\
\text { Social Media, } \\
\text { Politics, } \\
\text { Elections, } \\
\text { Voters, } \\
\text { Bibliometric. }\end{array}$ & $\begin{array}{l}\text { The increasing use of technological tools, have gained significant importance, } \\
\text { including social media. In the field of politics is no different, since after the } \\
2008 \text { U.S. elections the use of these tools became crucial in campaigns. } \\
\text { Several studies have turned to this theme, however, many of them investigate } \\
\text { how politicians used them, whether to mobilize voters, generate more } \\
\text { participation and/or engagement. In addition, field researchers say that recent } \\
\text { investigations are only turning to the context of political agents, deprecating } \\
\text { the reality of voters. In view of this movement found in the literature, this } \\
\text { study aimed to present and discuss scientific production, during the period } \\
\text { from } 2008 \text { to } 2020 \text {, on the themes: social media, elections and voters. The } \\
\text { survey points to a difference in the number of surveys conducted between the } \\
\text { scenarios, as well as indicates different ways for surveys to be developed in } \\
\text { the context of voters. }\end{array}$ \\
\hline
\end{tabular}

\section{Introdução}

É fato que a internet ganhou importância exponencial em diversos aspectos da vida nos últimos tempos, principalmente após a evolução das tecnologias de informação e comunicação (TIC), em que o acesso à internet $\mathrm{e}$

\footnotetext{
* Correspondência para autor:

daviisantana@gmail.com (Santana, D.P.) (ORCID: 0000-0002-2448-5618), profsales@hotmail.com (Sales, J.D.A.) (ORCID: 0000-0001-6305-8910), ale.cnogueira@gmail.com (Lima, A.C.N.) (ORCID: 0000-0002-2519-429X).
} 
a informação se tornou mais fácil, ultrapassando as limitações físicas e geográficas, ocasionando impacto em diversas esferas da sociedade, inclusive a política (CASTELLS, 2017).

Para Gomes et.al (2009) o efeito dos recursos tecnológicos sobre o campo político foi inicialmente modesto, haja vista uma pequena parcela de americanos acesso quando eles foram empregados nas campanhas eleitorais de 1992. A princípio, o uso da internet foi mínimo em campanhas eleitorais, exercendo apenas o papel de um serviço de correspondência a distância. Com o avanço da tecnologia desde o acesso a rede de computadores ate o surgimento das mídias sociais, as principais aplicabilidades da internet nesse contexto, passaram a ser os sites dos políticos, com atividades vinculadas aos bancos de dados, empregados somente para discursos, panfletos e outros materiais de campanha. De qualquer modo, eles deram início as interações e participações online, com possibilidade de feedbacks e arrecadação de recursos para as campanhas (GOMES.

Outra evolução desse ambiente, é a transferência de apenas um site de compartilhamento de informações para sites de relacionamento, adotando assim um novo modus operandi para as campanhas, o formato cooperativo, em que a participação dos internautas assumia um domínio, tornando as mídias sociais, o principal intermediário da interação candidatos/cidadãos. (GOMES et al., 2009; GIBSON, 2015).

Com o advento das mídias sociais, sendo estas um espaço criado pelos próprios usuários, o que permite maior interatividade, comunicação, troca e compartilhamento de informações é dificil falar de política sem emvolve-las (KAPPOR et al., 2018). Através delas, as pessoas emitem opinião pelas plataformas, políticos as utilizam para divulgar trabalhos realizados e fazer campanha eleitoral, os assuntos tratados nas mídias sociais são divulgados nas mídias tradicionais. Dessa forma, os partidos políticos, começaram a utilizá-las como uma forma de comunicação adicional para disseminação de ideias, mobilização de campanha e para reconectarem-se com os seus partidários, bem como com novos eleitores (BÉLANGUER, 2019). Logo, é inevitável ignorar o impacto dessas ferramentas dentro do contexto político e social (ENLI, 2017; AMARAL; PINHO 2018).

Diante disso, pesquisas foram elaboradas visando entender qual o impacto das novas tecnologias no cenário político. Hosch et al (2016) dividem os estudos em duas vertentes, os voltados para a perspectiva do político e os para a perspectiva dos eleitores, oferta e demanda, respectivamente. Quando se fala em estudos direcionados para a oferta, geralmente trata-se de assuntos como o uso das mídias sociais como estratégia de campanha, a exemplo de Enli (2017), que em seu estudo investiga as estratégias utilizadas nas eleições pelos candidatos Hillary Clinton, do partido democrata, e o republicano Donald Trump no Twitter; de Fernandes et al. (2018) que fizeram uma análise nas fanpages, isto é, páginas do Facebook abertas para o público, dos principais candidatos a prefeito de Belo Horizonte, considerando o primeiro turno como base em que foram analisados os conteúdos mais acionados e os formatos mais utilizados pelos candidatos. Nesse mesmo sentido, Amaral e Pinho (2018) analisaram o comportamento dos políticos brasileiros no ambiente virtual durante as eleições parlamentares de 2014, os autores identificaram que, em momentos próximos a campanha eleitoral, os políticos ficam mais ativos nas mídias sociais, buscando maior visibilidade.

Já na segunda perspectiva, a dos eleitores, os temas abordados vão desde o impacto das mídias na participação (TOWNER, 2013; GIBSON, 2015; MOURA; MICHELSON, 2017), na mobilização (STRANDBERG, 2013; ALDRICH et al., 2016; SEGESTEN; BOSSETTA, 2017; ALLSOP; KISBY, 2019), no engajamento (GOODMAN et al., 2011; BEKAFIGO; MCBRIDE, 2013; BIMBER, 2014; VACCARI, 2017), e no uso das mídias sociais como fonte de informação (SHERMAN; SCHIFFMAN; THELEN, 2012; ANDI; AYTAÇ; ÇARKOGLU, 2019; BÉLANGER, 2019; OHME, 2020) até sobre a discussão a respeito do potencial que as mídias podem ter na ampliação da democracia (KAUN; GUYARD, 2011; BAXTER et al., 2013; KOC-MICHALSKA; GIBSON; VEDEL, 2014).

Apesar da relevância dessa última abordagem, a maior parte dos estudos são voltados para a primeira vertente (HOSCH, et al., 2016; BOULIANNE, 2018; BÉLENGUER, 2019). Na literatura brasileira não é diferente, as pesquisas são direcionadas para a análise de como é feito o uso das ferramentas da internet nas campanhas online, a adesão dessas tecnologias pelos candidatos e partidos, como também para a análise do conteúdo que ocorre dentro das mídias digitais entre eleitores e candidatos (SANTANA, 2018). salienta-se o trabalho de Bélanguer (2019), o qual, além da deficiência anteposta, avulta que a maioria dos trabalhos ligados aos eleitores só exploram o quesito da participação e não as outras possibilidades, sendo a partir da perspectiva, dos eleitores que se configura o foco de investigação do presente trabalho.

Portanto, tendo em vista o cenário científico outrora exposto, realizou-se uma investigação bibliométrica a partir do seguinte questionamento: como a produção científica sobre o tema mídias sociais e eleições, 
especificamente para o contexto dos eleitores, se desenvolveu no período compreendido entre os anos de 2008 a $2020 ?$

A construção e o desenvolvimento do conhecimento científico acontecem de maneira contínua, analisando o que já foi pesquisado. A busca pela síntese dos resultados de trabalhos anteriores é fundamental para dar continuidade e desenvolver o campo de pesquisa que está sendo estudado. O mapeamento científico surge como uma forma de auxiliar os métodos já usados por estudiosos para fazer suas revisões. Esse mapeamento se baseia em uma abordagem quantitativa, usando os métodos bibliométricos, que buscam auxiliar novos pesquisadores a entender a estrutura de um campo e introduzir um rigor científico quantitativo na revisão da literatura tradicional (ZUPIC; CARTER, 2015).

A próxima seção do artigo fornece uma visão geral do método empregado para a realização da pesquisa. A seção que a segue discute os resultados obtidos, fruto das análises de publicações, citações e co-citações. Posteriormente são descritas algumas lacunas encontradas nos estudos para o desenvolvimento das pesquisas e, por fim, são apresentadas as conclusões deste trabalho.

\section{Procedimentos Metodológicos}

Para a concretização da análise bibliométrica realizou-se um protocolo partindo da definição das bases de dados. Foram selecionadas duas bases: Scopus e Web of Science (WoS), escolhidas em virtude da abrangência, por envolverem diversas áreas do conhecimento e por ambas serem indexadas. Além disso, elas permitem a exportação dos metadados necessários para as análises de publicações e citações (ZUPIC; CATER, 2015). Para consecução da pesquisa, as buscas foram estruturadas em três palavras chaves, seno a intersecção das três a literatura de interesse, como é mostrado na Figura 1. As palavras chaves foram: mídias sociais, eleição e eleitores e suas variações, culminando na seguinte string: (("Social Media" OR "digital social network*") AND election* AND (voter* OR elector*)).

Figura 1 - Literatura de Interesse

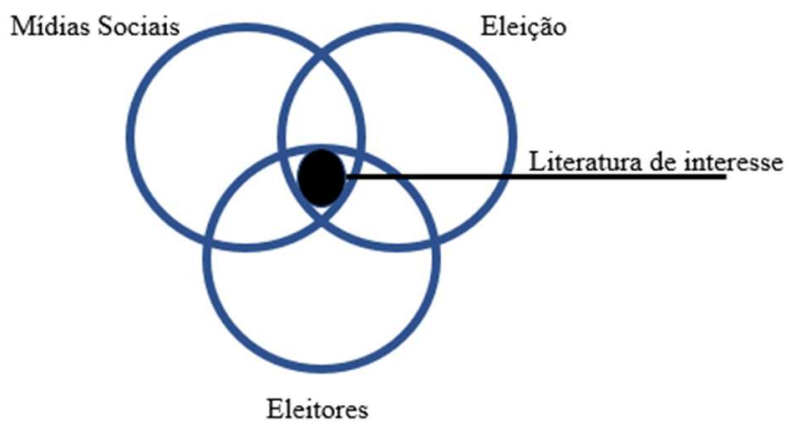

Fonte: Elaborado pelo autor (2020)

Perante a grande variedade de áreas de estudo que o tema da pesquisa percorre, foi necessário reduzi-las para limitar as áreas Ciências Sociais e Negócios, Gestão e Contabilidade. Em seguida, mais um filtro foi aplicado, relacionado ao tipo de documento, optando-se apenas por artigos. Também foi delimitada a linha temporal de 2008 até o corrente ano, 2020. O ano de 2008 foi escolhido por ser o marco do início da popularização do uso das mídias em campanhas políticas (ENLI, 2017; AMARAL; PINHO 2018), mesmo que antes já tinham sido usadas outras formas de mídias na internet, a exemplos de blogs e e-mails (GIBSON, 2004; BIMBER, 2014). Vale destacar que a coleta de dados foi realizada nos meses de março e abril do ano de 2020.

Após essas definições, foram colhidos os metadados de cada base, sendo 271 artigos da Scopus e 306 da Web of Science, totalizando 575 artigos, para agilizar o processo de triagem e limpeza dos dados foi utilizado o software EndNote X9, isso possibilitou identificar os artigos duplicados. Configurando a amostra inicial em 398 artigos, a fim de eleger os artigos e dar continuidade ao trabalho, foi feita a leitura do título e resumo, quando necessário, da metodologia e conclusão do estudo, de modo a verificar a associação dos trabalhos ao objeto da pesquisa. 
Os artigos que não tiveram, no seu escopo, relação com um dos eixos da pesquisa foram excluídos, tendo como amostra final da pesquisa 64 artigos. A maioria dos textos eliminados eram de pesquisas relacionadas a oferta e não a demanda. É importante salientar que outro critério para inclusão foi o de artigos em acesso gratuito.

Após a definição da amostra, os metadados foram tradados no EndNote X9, com a finalidade de ajustar possíveis erros de nomes, seja dos autores ou dos Journals. Feita essa etapa, aplicou-se o software para mapeamento bibliométrico Vosviewer, no qual foram analisadas as redes de citações. Além disso, foi usado o software Microsoft Excel para confecção de tabelas e gráficos, de forma a melhor visualizar os achados.

A análise que deu início ao processo foi a de quantidade de publicações, sendo separada de duas formas: a primeira teve por base a quantidade total de artigos publicados por ano, após a etapa da triagem com o intuito de observar o crescimento de uma forma geral do campo, enquanto a segunda, foi realizada apenas nos artigos selecionados para a amostra, que foi a análise de publicações por periódicos, permitindo verificar quais os periódicos que mais publicam sobre o tema (LOPES; CARVALHO, 2012; KAPPOR, et al., 2018).

Após análise de publicações, foi feita a análise de citações com o intuito de identificar o impacto, principais autores e referências (KAPPOR, et al., 2018). Para avaliar os artigos mais relevantes, dentre os selecionados, foi realizado o cálculo de índice corrigido de citações baseado na equação de Lopes e Carvalho (2012): $I C c=I C \times(F+1)$.

$\mathrm{Na}$ equação do índice corrigido, onde IC é o índice de citação extraído de cada base de dados e F é o fator do periódico em que o artigo foi publicado. O objetivo dessa correção é incluir, além do índice de citação, a relevância do periódico e, assim, ter maior precisão sobre qual trabalho tem um impacto maior (LOPES; CARVALHO, 2012). Cada base de dados possui um fator específico, para medir o impacto do Journal, na WoS é o JCR, feito pelo Journal Citation Reports, e o da Scopus é o SJR, realizado pelo SCImago Journal Rank. Por isso foi feita análise separada das duas bases.

Em seguida, foi realizado a análise de co-citação com o auxílio do Vosviewer. que é capaz de identificar a base do conhecimento, as principais referências de um determinado campo ou tópico de pesquisa (ZUPIC; CATER, 2015; KAPPOR, et al., 2018). A amostra continha uma diversidade de referências citadas, diante disso, foi colocado um filtro com um número de citações no Vosviewer. Para a WoS o número de corte de 4 citações e para a Scopus 2 citações, uma vez que esta última possuía um baixo número de referências citadas.

\section{Resultados}

Nesta seção serão apresentados e analisados os principais resultados das análises, previamente realizadas, de publicações e citações dos artigos selecionados. Além disso, serão descritos os principais trabalhos encontrados, visando fornecer, àqueles que consultem o presente artigo, um direcionamento acerca de onde obter material sobre algum dos temas ou tópicos abordados.

\subsection{Análise das publicações}

Ao fazer a análise de publicações percebe-se que há um crescimento no número de publicações ao longo dos anos, como é apresentado no gráfico 1. Esse gráfico teve como base os 398 artigos que sobraram após a primeira triagem.

Gráfico 1 - Publicações por ano 2008 - 2020

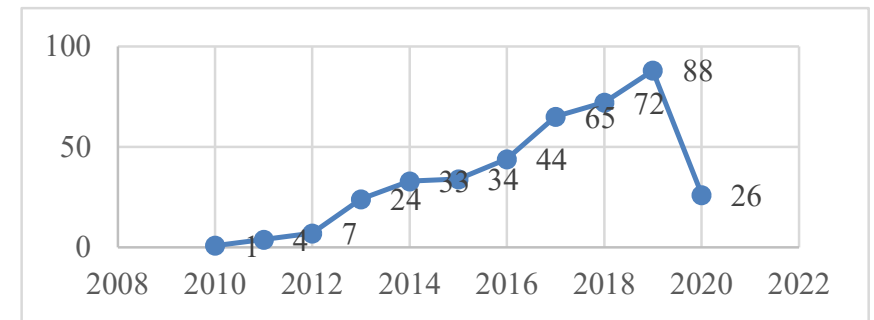

Fonte: Elaborado pelo autor (2020)

No entanto, quando se faz essa mesma análise com os 64 artigos que compõem a amostra desta pesquisa, percebe-se que ao restringir o contexto apenas para artigos que tratam dos eleitores, o número cai de maneira 
significativa, corroborando o que é dito pelos autores Hosch, et al. (2016), Santana (2018), Boulianne (2018), e Bélanguer (2019).

Em sequência, buscou-se identificar quais periódicos foram publicados os artigos da amostra, e obtevese 45 periódicos diferentes, evidenciando assim, a grande quantidade de periódicos passíveis de publicação, no entanto não houve nenhum periódico brasileiro.

Desta descoberta, percebeu-se que os 9 periódicos com mais publicações concentram 28 artigos dos 64 que compoem a amostra, do décimo em diante cada um só apresentou um artigo publicado. O periódico com maior número de publicações é o Journal of Information Technology \& Politics, com 7 artigos, seguido do New Media \& Society e do Social Science Computer Review ambos com 4, do Information Communication \& Society com 3 $e$ dos Political Communication, Telematics and Informatics, Party Politics e Societies, Jornal of Political Marketing com 2 publicações em cada.

\subsection{Análise das Citações}

Quanto a análise de citações, esta foi feita com base na equação 1, com isso, foram separados os 10 artigos com maior ICc da WoS e os 10 artigos com maior ICc da Scopus. A Tabela 1 mostra a lista dos artigos mais citados na base de dados WoS, enquanto a tabela 2 mostra o índice dos artigos mais citados da base de dados Scopus. Os trabalhos são apresentados em ordem, conforme as tabelas.

Tabela 2 - Lista de artigos mais citados na base de dados WoS (fator de impacto JCR referente ao ano de 2018).

\begin{tabular}{llccc}
\hline Autores & Journals & IC & JCR & ICc \\
\hline Strandberg (2013) & New media \& society & 63 & 4,800 & 365,4 \\
Bekafigo e McBride (2013) & Social Science Computer review & 66 & 2,922 & 258,9 \\
Gibson (2015) & Party politics & 62 & 2,615 & 224,1 \\
Groshek e Koc-Michalska (2017) & Information communication \& society & 40 & 4,124 & 205,0 \\
Kruikemeier et al (2014) & New media \& society & 34 & 4,800 & 197,2 \\
Towner (2013) & Social science computer review & 49 & 2,922 & 192,2 \\
Vaccari (2017) & Political communication & 17 & 4,339 & 90,8 \\
Aldrich et al. (2016) & Party politics & 24 & 2,615 & 86,8 \\
Hosch et al. (2016) & Social science computer review & 18 & 2,922 & 70,6 \\
Segesten e Bossetta (2017) & Information communication \& society & 12 & 4,124 & 61,5 \\
\hline
\end{tabular}

Fonte: Elaborado pelo autor (2020)

O estudo que teve o maior índice foi o de Stradberg (2013), o objetivo da pesquisa foi avaliar o uso das mídias sociais e o desenvolvimento da campanha online. $\mathrm{O}$ autor analisa as mídias sociais com base nas teorias de normalização e equalização, que são relativas à estrutura online de campanha (políticos), e as teorias de reforço e mobilização, relacionadas a ações políticas (eleitores). A teoria da equalização sugere que as mídias sociais seriam capazes de equalizar, deixar no mesmo nível, todos os candidatos, dos mais populares aos pequenos, que fizessem uso delas. Em contrapartida, na normalização parte do pressuposto que no ambiente das mídias sociais seria reproduzido o que acontece no mundo offline. Na vertente dos eleitores, a teoria da mobilização é referente a capacidade que as mídias teriam de informar, organizar e engajar aqueles que atualmente estão marginalizados do sistema político existente. A teoria do reforço afirma que a política online só afetaria cidadãos já engajados politicamente, tendo um impacto modesto na sociedade de maneira geral. No contexto do estudo, as eleições finlandesas de 2011, houve indícios de um potencial para a mobilização dos eleitores (STRADBERG, 2013).

Bekafigo e McBride (2013) pesquisaram a capacidade que o Twitter tem para incentivar a participação política durante as eleições. Os autores concluíram que, não só o Twitter, mas, as demais mídias sociais têm o potencial de engajar pessoas quando o assunto é política e potencializar o alcance dos mais engajados. Pra Gibson (2015), as mídias sociais estão introduzindo uma nova forma de fazer campanha: a campanha iniciada pelo cidadão (CIC), tendo como marco as eleições de 2008 , em que um formato diferente, mais colaborativo e com maior posicionamento dos eleitores, pôde ser identificado. A autora observou que a CIC pode estar ajudando a promover 
e definir um novo método de recrutar cidadãos, o online.

Groshek e Koc-Michalska (2017) examinaram como as mídias sociais podem ser utilizadas para ajudar os candidatos populistas, para isso, eles analisaram as eleições americanas de 2016. Os autores separaram os usuários das mídias sociais em três grupos: ativos, passivos e não civis. Entende-se por usuários com participação ativa aqueles que são interativos, bidirecionais e criativos. Passivos são os que só leem, visualizam ou consomem conteúdo, de maneira passiva. Os não civis são aqueles que agem de maneira não civilizada dentro do ambiente digital, com insultos, por exemplo. Averiguou-se que o uso ativo das mídias sociais na política estava relacionado a pouco apoio aos candidatos populistas, mas as formas passivas e não civis estavam ligadas ao aumento da probabilidade de apoio. Um ponto interessante dessa pesquisa é que os considerados não civis tinham uma rede de contatos mais heterogênea, porém, eles só constroem essa rede diversificada com a intenção de insultar ou de entrar em situações de conflito e não de aceitar/respeitar outros pontos de vista.

Kruikemeier et al. (2014) investigam os efeitos das formas de uso ativa e passiva da internet e seu impacto no envolvimento político do cidadão e afirmam que ambas, têm efeito positivo no envolvimento político. Destacam ainda que aqueles com posicionamento mais ativo tendem a ter um envolvimento prévio com política, enquanto os passivos passam a ter ligação devido ao consumo das informações. Outras pesquisas que buscaram empiricamente entender como as mídias sociais impactavam na participação tambem estão no ranking de maiores ICc, como a de Towner (2013) que analisou o uso das mídias sociais nas eleições americanas de 2012, concluindo que o emprego das novas mídias teve impacto no aumento da participação, tanto online quanto offline, dos jovens na campanha política. A autora investigou diversas plataformas de mídias sociais, a exemplo de Facebook, Twitter, Google+, e todos tiveram algum impacto na participação dos eleitores. Outra plataforma digital investigada pela autora foi o Youtube, que não teve qualquer impacto na participação, provavelmente por causa da sua menor mobilização política e poucas funções de envolvimento, dificultando o engajamento dos eleitores (TOWNER, 2013).

Já o estudo de Vaccari (2017) mostrou que a mobilização digital é uma peça fundamental para as pessoas se engajarem politicamente. $\mathrm{O}$ autor avalia a relação entre mobilização online e engajamento político fazendo uma análise comparativa entre três países diferentes: Alemanha, Itália e Reino Unido. Ele sugere que a mobilização feita de forma digital pode promover maior igualdade política ao envolver cidadãos marginais.

Aldrich et al. (2016) avançam sobre a eficácia do contato online dos eleitores, fazendo uma comparação entre os EUA e o Reino Unido. Nessa comparação, os autores expõem que o impacto do contato online, do uso das mídias sociais, é mais desenvolvido nos EUA do que no Reino Unido, indicando que as campanhas americanas mantêm o status de vanguarda na adoção e no uso das novas tecnologias no pleito eleitoral. Acrescentados pelos estudos de Hosch et al. (2016) que analisam o potencial mobilizador do Twitter nas campanhas holandesas de 2012, confirmando que ela é uma importante ferramenta para ensejar a participação cidadã. Dentre os seus resultados, os autores apontam que os cidadãos são visíveis nas campanhas on-line, ou seja, a sua participação tem cada vez mais influência.

O estudo de Segesten e Bossetta (2017), publicado no Journal Information communication \& Society, porta um alto valor de impacto. Teve como foco de pesquisa o uso da mídia social Twitter, por parte do cidadão, como forma de mobilização política. Eles investigaram os tipos de mensagens enviadas pelos usuários e como elas impactaram outras pessoas interligadas na rede. Com isso, evidenciaram que são os cidadãos que iniciam e compartilham apelos políticos e ações até a eleição e não os partidos políticos.

Na tabela 3 está a lista dos artigos mais citados com base no ICc da base de dados Scopus. Estão separados 10 artigos porque os demais não tiveram nenhuma citação.

Tabela 3. Lista de artigos mais citados na base de dados Scopus (fator de impacto SJR referente ao ano de 2018).

\begin{tabular}{llrrr}
\hline Autores & Journals & IC & SJR & ICc \\
\hline Bimber (2014) & Journal of Information Technology and Politics & 89 & 1,142 & 190,6 \\
Grover et al. (2019) & Technological Forecasting and Social Change & 35 & 1,422 & 84,8 \\
Koc-Michalska, Gibson & e Vedel & & & \\
(2014) & Journal of Information Technology and Politics & 35 & 1,142 & 75,0 \\
Raynauld e Greenberg (2014) & Journal of Information Technology and Politics & 26 & 1,142 & 55,7 \\
Štětka, Mazák (2014) & Cyberpsychology: Journal of Psychosocial Research on & 17 & 0,595 & 27,1
\end{tabular}




\begin{tabular}{|c|c|c|c|c|}
\hline & Cyberspace & & & \\
\hline Ohme (2020) & Digital Journalism & 3 & 2,669 & 11,0 \\
\hline Copeland e Römmele (2014) & Journal of Information Technology and Politics & 3 & 1,142 & 6,4 \\
\hline Kaun e Guyard (2011) & International Journal of Electronic Governance & 3 & 0,318 & 4,0 \\
\hline Sherman, Schiffman e Thelen & & & & \\
\hline (2012) & Journal of Political Marketing & 2 & 0,544 & 3,1 \\
\hline Strandberg e Carlson (2017) & Scandinavian Political Studies & 1 & 0,488 & 1,5 \\
\hline
\end{tabular}

Fonte: Elaborado pelo autor (2020)

Quanto ao artigo mais citado da Scopus, o trabalho de Bimber (2014) é um ensaio teórico sobre os papéis das mídias sociais nas duas campanhas presidenciais de Obama, 2008 e 2012. O estudo é feito com base em dois temas: comunicação política personalizada e mercantilização da mídia digital como ferramenta. Nesse trabalho, o autor colheu, outros trabalhos para entender como as mídias são utilizadas, tanto pelos políticos, quanto pelos cidadãos, dando um panorama geral, com base no recorte temporal, sobre como as mídias estão, de fato, na política.

Dentre todos os artigos, de ambas as plataformas, os mais citados geralmente são os mais antigos, contudo, o trabalho de Grover et al. (2019) é o segundo da lista na base Scopus. Nele, os autores, tomando como estudo de caso as eleições de 2016 dos Estados Unidos, analisam o uso do Twitter nas campanhas políticas e como os fatores presentes nessa plataforma refletiriam no comportamento do eleitor. Eles concluíram que, de fato, a plataforma impacta o comportamento do eleitor, consequentemente tem influência direta nos resultados das eleições. Ademais, destacam que as discussões na plataforma têm polarizado os usuários e a análise das mídias sociais tem sido usada para obter ideias sobre as eleições dos Estados Unidos.

Koc-Michalska, Gison e Vedel (2014) investigam o uso da web pelos cidadãos durante duas campanhas eleitorais francesas, a primeira em $2007 \mathrm{e}$ a segunda em 2012. Os resultados refletem um ponto importante para a tese da normalização, percebeu-se um maior uso das ferramentas online de uma eleição para outra. Esse crescimento ajudou nas campanhas políticas dos candidatos menores, que superaram os principais concorrentes, mostrando assim o potencial das novas tecnologias.

Dentre as mídias sociais, uma das que mais chama a atenção no cenário político e está mais presente nos estudos que envolvem a área é o Twitter. Raynauld e Greenberg (2014) investigam o uso dessa plataforma nas eleições municipais de Ottawa, no estado de Ontário, Canadá. O trabalho oferece uma visão da possível transformação que vem acontecendo nas campanhas políticas, com a maior presença dos cidadãos que usam as plataformas das mídias sociais para serem mais ativos na política e não somente nas eleições.

Štětka e Mazák (2014) examinam a relação entre a expressão política online e formas de participação offline, teoricamente fundamentados em autores que falam do papel das mídias sociais na participação política e engajamento cívico, incluindo também as teses de mobilização e normalização. Como principal resultado, eles identificaram que as pessoas ativas politicamente através das mídias sociais, igualmente são mais propensas a participar nas eleições, seja em conversas online e/ou offline, seja na votação ou em manifestações.

Ohme (2020) explorou como o eleitorado, nas eleições nacionais dinamarquesas de 2015, foi informado e mobilizado pelo uso das mídias sociais durante a campanha. Ele fez uma comparação entre eleitores experientes e eleitores jovens, que teriam sua primeira experiência em uma eleição, chamados por ele de nativos digitais. Ficou evidenciado que os eleitores iniciantes recebem informações, principalmente, via mídias sociais, portanto, esta é a principal fonte de informação dos jovens eleitores.

Os autores Copeland e Römmele (2014) examinaram as pessoas que viam informações sobre festas e campanhas políticas através das mídias sociais e as compartilhavam através da mesma ferramenta. Foi um dos poucos estudos longitudinais, aplicado nas eleições alemãs de 2009. Os resultados confirmaram que uma parte do eleitorado alemão recebia informações políticas e de campanha por meio das mídias sociais. As pessoas engajadas politicamente e de alguma maneira comprometidas com um partido político, estavam mais propícias a compartilhar e ver as informações por meio das mídias sociais, sendo os jovens os mais expostos a esse tipo de conteúdo. Os pesquisadores apontaram que as informações compartilhadas pelos meios digitais não alcançam só os membros mais jovens, como também pessoas que não tivessem ligações com um partido.

Já Kaun e Guyard (2011) discutem o potencial democrático das mídias sociais nas eleições, revelando que os estudantes não viam o ambiente digital como local para debates políticos, usando-o, principalmente, como 
forma de socializar com amigos. Segundo os autores, engajamento político sério seria encontrado em outros lugares, além disso, concluíram que os jovens percebem as mídias tradicionais como uma fonte mais confiável de informação política. Sherman, Schiffman e Thelen (2012) exploraram a confiança de jovens eleitores nos veículos de mídia de informação nas eleições presidenciais de 2008. Eles compreenderam que as mídias sociais haviam ganhado força e espaço no meio político, contudo, os respondentes ainda não a consideravam um ambiente de confiança para conversar e debater política.

Já Strandberg e Carlson (2017) estudam como e se a procura por informação política online mudou ao longo do tempo, buscando especificamente indicações de um efeito mobilizador ou reforçador. Eles examinaram o período de 2003 a 2015, passando por diferentes momentos do uso da tecnologia no meio político. De modo geral, o resultado mostra que para haver buscas por informações era necessário ter alto interesse político, alto nível de atividade política e tenra idade, fatores estes que se mantiveram ao longo do tempo. Tratando das mídias sociais, os autores destacam que o interesse político e a atividade política tornaram-se preditores de informação ligeiramente mais fortes. A prevalência por fatores atitudinais é interessante, uma vez que as mídias sociais são consideradas como tecnologias que ignoram o requisito de escolha ativa dos usuários para encontrar conteúdo online (STRANDBERG; CARLSON, 2017).

\subsection{Análise de co-citação}

A análise dos trabalhos mais citados permitiu identificar quais são os trabalhos com maior representatividade dentro da área pesquisada, por sua vez, a análise de rede de co-citação permitiu detectar os trabalhos mais citados pelos autores da amostra final, destacando a importância deles. A análise de co-citação é utilizada para identificar e explicar a estrutura conceitual de um determinado tema. O pressuposto subjacente nesse tipo de análise é que quando os autores estão em um mesmo grupo (cluster) eles trabalham conceitos semelhantes (KAPPOR, et al., 2018). A figura 3 mostra o resultado dos dados analisados da base de dados da Web of Science. O VosViewer encontrou 3 grupos, lembrando que foi colocado um filtro de no mínimo 4 citações, na própria ferramenta:

Figura 3 - Rede de Co-citação (WoS)

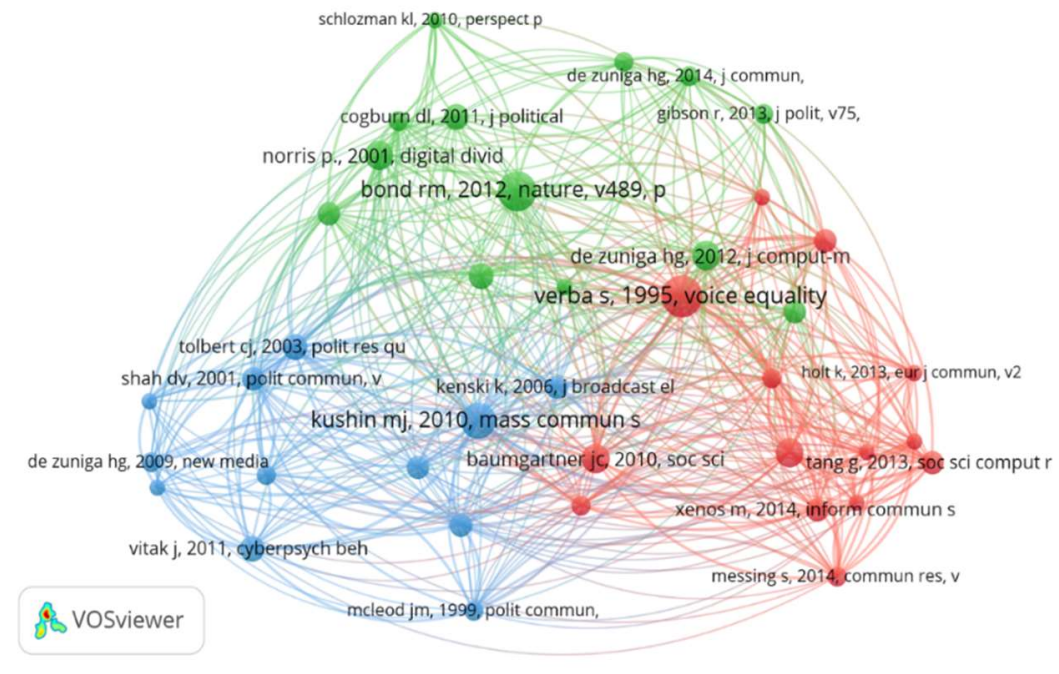

Fonte: Elaborado pelo autor (2020)

Cluster 1 (Vermelho): os autores desse cluster contribuíram para pesquisas relacionadas as mídias sociais como fonte de notícias e como forma de engajar os jovens na política a exemplo de Baumgartner e Morris (2010). Messing e Westwood (2012) analisaram as influências dos atores políticos e da heterogeneidade de rede na participação nas eleições. Tang e Lee (2013) verificaram o uso do Facebook como ferramenta política e o impacto das informações políticas compartilhadas nessa mídia social. E os autores Xenos, Vromen e Loader (2014) estudaram a influência das mídias na socialização e no engajamento político dos cidadãos.

Cluster 2 (Verde): os autores desse cluster contribuíram para estudos como a representatividade da participação política na internet, como é o caso dos autores Best e Krueger (2005). Já Boulianne (2009) investigou 
se a internet impactava no engajamento político com base em outros estudos. Bond (2012) analisa o impacto das mensagens que são enviadas no Facebook na influência da auto expressão política. Esse estudo investigou 61 milhões de usuários do Facebook e comprovou que o compartilhamento de mensagens por intermédios das mídias sociais influenciou a auto expressão política, a busca por informações e o comportamento do voto.

Cluster 3 (Azul): alguns autores presentes nesse cluster contribuíram para estudos relacionado à internet como fonte de informação política, como é o caso de Kushin e Yamamoto (2010). Shah, Kwak e Holbert (2001) almejaram entender como a internet pode mudar a vida cívica e o cotidiano das pessoas e Kenski e Stroud (2006) o efeito do acesso e da exposição à internet, investigando se estão associados a eficácia política, conhecimento e participação.

A figura 4 representa a rede de co-citação das referências dos artigos da base de dados Scopus. Devido ao baixo número de artigos exportados da base, só foi possível criar um único cluster com artigos de maior similaridade e com conexão. Nessa análise, o filtro aplicado foi de 2 citações. Outros artigos foram encontrados, todavia, ficaram de fora da rede por não possuir correspondência com o tema.

Figura 4 - Rede de Co-citação (SCOPUS)

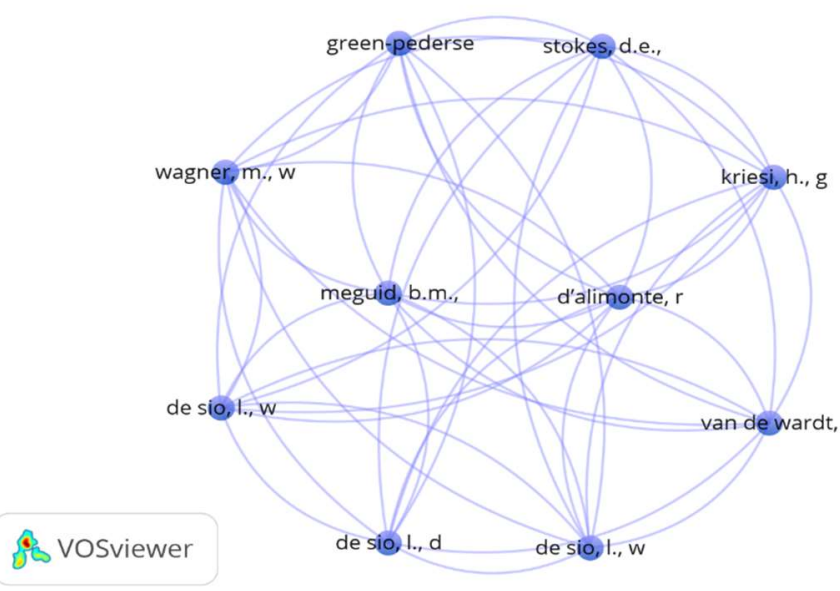

Fonte: Elaborado pelo autor (2020)

Cluster 1: esse cluster é composto por autores que lidam com uma variedade de questões que não estão relacionadas diretamente com as mídias sociais, mas falam sobre a mudança no ambiente político, posições e estratégias partidárias, extremismo e polarização política. Kriesi et al. (2006) estudaram o processo de globalização e o novo conflito estrutural que esse fenômeno causou nos países da Europa Ocidental. Pedersen (2007) examinou a mudança na competição política partidária, a qual, devido as mudanças na sociedade, deixou de ser uma disputa por causas socioeconômicas, para ser uma competição por questões, como por exemplo, o aborto. Wagner (2012) estuda sobre os incentivos estratégicos que as partes políticas recebem para adotar posições extremas. Sio e Weber (2014) também avaliam a estratégia partidária, mais precisamente a estratégia por questões, e constataram que essa forma de trabalhar os problemas políticos acontecem em diferentes contextos em toda a Europa.

\subsection{Limitações e considerações referentes aos trabalhos analisados}

É comum que os estudos científicos exponham as lacunas da pesquisa e a partir delas proponham pesquisas futuras. Deste modo, com base nos artigos analisados, destaca-se algumas das lacunas encontradas:

Estudos como o de Ohme (2020), que examinou o impacto do uso de notícias móveis, ou seja, notícias que são visualizadas mediante o uso de um aparelho mobile, na participação e no conhecimento político, alertaram para os tipos de perguntas utilizadas. $\mathrm{O}$ autor alega que as perguntas feitas tinham relação aos acontecimentos, para o período do estudo, recentes em evidência nas mídias, logo, isso possibilitaria um maior conhecimento por parte dos respondentes. Como sugestão, pesquisas futuras deveriam avaliar os efeitos do consumo de notícias móveis em diferentes tipos, como conhecimento episódico e temático (OHME, 2020). Andi, Aytaç e Çarkoglu (2019) também pesquisaram os efeitos do uso da internet e das mídias sociais no conhecimento político. Eles relatam que devido a quantidade de estudos quantitativos seria interessante, para complementar a análise por eles apresentadas, 
realizar uma pesquisa qualitativa.

Ohme, Vreese e Albaek (2018) analisam o efeito da exposição nas mídias na formação de jovens pela escolha do voto. Os autores destacam que só investigaram os efeitos no momento da votação, sendo assim, pesquisas futuras devem investigar os efeitos em momentos distintos de uma campanha eleitoral, buscando novos fatores, de modo que a pesquisa seja mais detalhada. Hosch et al. (2016), que pesquisaram sobre o comportamento político dos eleitores nas mídias sociais, com foco no Twitter, sugerem um caminho de pesquisa futura baseado na análise de redes de retweet para descobrir até que ponto diferentes grupos de usuários retuitaram os tweets de campanha negativos e persuasivos de cada um. A combinação desses métodos com a análise de conteúdo de tweets poderia, por exemplo, aprofundar a compreensão da chamada campanha iniciada pelo cidadão.

Bélanger (2019) examinou se o uso das mídias sociais está relacionado a intenção de voto durante as campanhas eleitorais. Primeiro, o autor destaca a pouca atenção que é dada para o comportamento da votação, ou seja, como os eleitores tomam a decisão de qual partido ou candidato votar. Como sugestão de pesquisa futura, o autor ressalta a importância de buscar o estabelecimento de um vínculo mais direto entre as atividades online do partido político e o uso das mídias sociais pelos eleitores.

\section{Considerações finais}

Este artigo apresenta e discute trabalhos contribuindo para literatura que estuda o impacto das mídias sociais nas eleições, de forma específica, no contexto dos eleitores. Os resultados encontrados corroboram com as alegações de Hosch, et al. (2016), Santana (2018), Boulianne (2018) e Bélanguer (2019), uma vez que, proporcionalmente o número de artigos encontrados no contexto dos políticos é muito maior do que no contexto dos eleitores. Mesmo com a delimitação da pesquisa, apenas $16,3 \%$ dos artigos encontrados tinham relação com os eleitores. Mesmo assim, esse fato não significa que existam poucos trabalhos, ou ainda, que é um campo pouco explorado, porém, acredita-se haver caminhos diferentes a serem percorridos.

A análise de publicações permitiu observar a evolução do tema em causa, com uma crescente quantidade de artigos publicados ao longo do ano. Possibilitou também a identificação dos periódicos mais relevantes. Considerando o escopo de cada periódico destacado neste estudo, a exemplo de Social Science Computer Review, Societies e Information Communication \& Society, demonstra-se que esse tema de estudo é multidisciplinar e importante para diversas áreas de conhecimento, não só para as ciências sociais.

Ao revisar as publicações reunidas para este trabalho foram detectados pontos em comum em inúmeros aspectos. Observou-se que a maioria dos trabalhos da amostra final tratavam sobre a participação política, seguido de engajamento e mobilização, endossando as considerações de Bélanguer (2019), o qual expôs que a maioria das pesquisas realizadas na área, quando se tratava de mídias sociais nas eleições referente aos eleitores, abordavam o impacto dessas ferramentas na participação política do eleitorado. Além disso, essa análise identificou que o método de pesquisa dominante foi o quantitativo, com coleta de dados transversais, algo apontado por muitos estudos como uma das limitações. Sendo assim, é possível concluir que a área carece de estudos com recortes longitudinais e com uma abordagem qualitativa.

No decorrer da pesquisa poucos estudos de autores brasileiros foram encontrados. A maioria deles foram excluídos da amostra final por não se enquadrarem aos critérios estabelecidos. O único estudo realizado por pesquisadores brasileiros foi onde Moura e Michelson (2017). Eles investigaram o impacto do uso de vídeos curtos, compartilhados pelo Whatsapp, como forma de aumentar a participação de eleitores adolescentes.

Ao analisar os artigos por ordem cronológica de publicação, percebe-se que, após 2008, a importância e o impacto que as plataformas de mídias sociais têm dentro do arcabouço político e nas eleições aumentaram. Inicialmente vistas como uma fonte secundária de informações, apenas uma ferramenta para auxiliar os políticos, mas ao decorrer do tempo, passaram a ser instrumentos essenciais durante as campanhas, com impactos expressivos, tanto para os políticos quanto para os eleitores. Além disso, na análise de co-citação, principalmente com os artigos da Scopus (figura 3), os estudos presentes no cluster tem sua atenção voltada para as estratégias partidárias e como elas se moldaram após o surgimento das novas tecnologias e o fenômeno da globalização.

Esta pesquisa se mostrou limitada quanto as bases de dados. Estudos futuros podem explorar uma quantidade maior de bases, principalmente aquelas que englobem mais trabalhos brasileiros, a fim de entender como são as pesquisas desenvolvidas no Brasil, suas estruturas e as diferentes possibilidades de mídias a serem estudadas. Acrescenta-se que a maioria dos estudos investigados desenvolvem suas pesquisas com base em duas plataformas de mídias sociais, o Facebook e o Twitter, pouco se fala de Instagram e só há um trabalho que lida com o aplicativo de mensagens WhatsApp, o de Moura e Michelson (2017). As próximas investigações podem se 
debruçar sobre as diferentes mídias existentes e explorá-las com maior detalhe, percebendo o impacto causado por elas nas eleições.

Nesta bibliometria, para fazer a análise de citações e de impacto, foram usadas as métricas de cada uma das bases de dados, WoS e Scopus. Sugere-se, para pesquisas futuras, utilizar como base o índice H do Google Scholar, pois seria uma maneira de unificar o parâmetro de análise e poder comparar artigos de bases diferentes.

Assim, ficou evidente que a política, as eleições, a democracia, o processo político, são diretamente influenciados e podem ser modificados pela informação, comunicação e emissão de opinião. As mídias sociais criam um ambiente propício para todos esses acontecimentos devido as suas características. Com a expansão do seu uso por uma grande parcela da sociedade, é importante que as próximas pesquisas realizem trabalhos que investiguem o impacto das mídias sociais com os aspectos mais intrínsecos ao usuário, a influência que ela tem sobre o comportamento, opinião, conhecimento, discussões. Ademais, espera-se que o conteúdo aqui exposto sirva como um direcionador para o desenvolvimento de mais pesquisas nesse campo de estudo.

\section{Referências}

ALDRICH, J. H.; GIBSON, R. K.; CANTIJOCH, M.; KONITZER, T. Getting out the vote in the social media era: Are digital tools changing the extent, nature and impact of party contacting in elections? Party Politics, v. 22, n. 2, p. 165-178, 2016.

ALLSOP, B.; KISBY, B. The "Youthquake" in British Politics: Myth or Reality? Societies, v. 9, n. 4, p. 68, 2019.

AMARAL, M. S; PINHO, J. A. G. Eleições Parlamentares no Brasil: O Uso do Twitter na Busca por Votos. Revista de Administração Contemporânea, v. 22, n. 4, p. 466-486, 2018.

ANDI, S.; AYTAC, S. E.; CARKOGLU, A. Internet and social media use and political knowledge: Evidence from Turkey. Mediterranean Politics, v. 25, n. 5, p. 579-599, 2019.

BAUMGARTNER, J. C.; MORRIS, J. S. MyFaceTube politics: Social networking web sites and political engagement of young adults. Social Science Computer Review, v. 28, n. 1, p. 24-44, 2010.

BAXTER, G.; MARCELLA, R.; CHAPMAN, D.; FRASER, A. Voters' information behaviour when using political actors' web sites during the 2011 Scottish Parliament election campaign. Aslib proceedings: New information perspectives, v. 65, n. 5, p. 515-533, 2013.

BEKAFIGO, M. A.; MCBRIDE, A. Who Tweets About Politics?: Political Participation of Twitter Users During the 2011 Gubernatorial Elections. Social Science Computer Review, v. 31, n. 5, p. 625-643, 2013.

BÉLANGER, É. Social media use and voting intention in the 2012 Quebec election campaign. French Politics, v. 17, n. 4, p. 468-481, 2019.

BEST, S. J.; KRUEGER, B. S. Analyzing the representativeness of Internet political participation. Political Behavior, v. 27, n. 2, p. 183-216, 2005.

BIMBER, B. Digital Media in the Obama Campaigns of 2008 and 2012: Adaptation to the Personalized Political Communication Environment. Journal of Information Technology \& Politics, v. 11, n. 2, p. 130-150, 2014.

BOND, R. M. et al. A 61-million-person experiment in social influence and political mobilization. Nature, v. 489, n. 7415 , p. 295-298, 2012.

BOULIANNE, S. Does Internet use affect engagement? A meta-analysis of research. Political communication, v. 26, n. 2, p. 193-211, 2009.

BOULIANNE, S. Twenty years of digital media effects on civic and political participation. Communication research, v. 47, n. 7, p. 947-966, 2020.

COPELAND, L.; RÖMMELE, A. Beyond the Base? Political Parties, Citizen Activists, and Digital Media Use in the 2009 German Federal Election Campaign. Journal of Information Technology \& Politics, v. 11, n. 2, p. 169-185, 2014.

DE SIO, L; WEBER, T. Issue yield: A model of party strategy in multidimensional space. American Political Science Review, v. 108, n. 4, p. 870-885, 2014.

ENLI, G. Twitter as arena for the authentic outsider: Exploring the social media campaigns of Trump and Clinton in the 2016 US presidential election. European journal of communication, v. 32, n. 1, p. 50-61, 2017.

FERNANDES, C. M. et al. A propaganda política no Facebook: O uso das fanpages pelos principais candidatos à 
Prefeitura de Belo Horizonte. Rizoma, v. 6, n. 1, p. 74-88, 2018.

GIBSON, R. K. Party change, social media and the rise of 'citizen-initiated'campaigning. Party politics, v. 21 , n. 2, p. 183-197, 2015.

GIBSON, R. K. Web campaigning from a global perspective. Asia-Pacific Review, v. 11, n. 1, p. 95-126, 2004.

GOODMAN, N.; BASTEDO, H.; LEDUC, L.; PAMMETT, J. H. Young Canadians in the 2008 Federal Election Campaign: Using Facebook to Probe Perceptions of Citizenship and Participation. Canadian Journal of Political Science-Revue Canadienne De Science Politique, v. 44, n. 4, p. 859-881, 2011.

GROSHEK, J.; KOC-MICHALSKA, K. Helping populism win? Social media use, filter bubbles, and support for populist presidential candidates in the 2016 US election campaign. Information Communication \& Society, v. 20, n. 9, p. 1389-1407, 2017.

GROVER, P.; KAR, A. K.; DWIVEDI, Y. K.; JANSSEN, M. Polarization and acculturation in US Election 2016 outcomes - Can twitter analytics predict changes in voting preferences. Technological Forecasting and Social Change, v. 145, p. 438-460, 2019.

HOSCH, B.; AMRIT, C.; AARTS, K.; DASSEN, A. How Do Online Citizens Persuade Fellow Voters? Using Twitter During the 2012 Dutch Parliamentary Election Campaign. Social Science Computer Review, v. 34, n. 2, p. 135-152, 2016.

KAPOOR, K. K et al. Advances in social media research: Past, present and future. Information Systems Frontiers, v. 20, n. 3, p. 531-558, 2018

KAUN, A.; GUYARD, C. Divergent views: Social media experts and young citizens on politics 2.0. International Journal of Electronic Governance, v. 4, n. 1-2, p. 104-120, 2011.

KENSKI, K; STROUD, N. J. Connections between Internet use and political efficacy, knowledge, and participation. Journal of broadcasting \& electronic media, v. 50, n. 2, p. 173-192, 2006.

KOC-MICHALSKA, K.; GIBSON, R.; VEDEL, T. Online Campaigning in France, 2007-2012: Political Actors and Citizens in the Aftermath of the Web.2.0 Evolution. Journal of Information Technology \& Politics, v. 11, n. 2, p. 220-244, 2014.

KRIESI, H. et al. Globalization and the transformation of the national political space: Six European countries compared. European Journal of Political Research, v. 45, n. 6, p. 921-956, 2006.

KRUIKEMEIER, S. et al. Unraveling the effects of active and passive forms of political Internet use: Does it affect citizens' political involvement? New Media \& Society, v. 16, n. 6, p. 903-920, 2014.

KUSHIN, M. J; YAMAMOTO, M. Did social media really matter? College students' use of online media and political decision making in the 2008 election. Mass Communication and Society, v. 13, n. 5, p. 608-630, 2010.

LOPES, A. P. V. B. V; CARVALHO, M. M. Evolução da literatura de inovação em relações de cooperação: um estudo bibliométrico num período de vinte anos. Gestão \& Produção, v. 19, n. 1, p. 203-217, 2012.

MESSING, S; WESTWOOD, S. J. Selective exposure in the age of social media: Endorsements trump partisan source affiliation when selecting news online. Communication research, v. 41, n. 8, p. 1042-1063, 2014.

MOURA, M.; MICHELSON, M. R. Whatsapp in brazil: Mobilising voters through door-to-door and personal messages. Internet Policy Review, v. 6, n. 4, p. 1-18, 2017.

OHME, J. Mobile but Not Mobilized? Differential Gains from Mobile News Consumption for Citizens' Political Knowledge and Campaign Participation. Digital Journalism, v. 8, n. 1, p. 103-125, 2020.

PEDERSEN, C. The growing importance of issue competition: The changing nature of party competition in Western Europe. Political studies, v. 55, n. 3, p. 607-628, 2007.

RAYNAULD, V.; GREENBERG, J. Tweet, Click, Vote: Twitter and the 2010 Ottawa Municipal Election. Journal of Information Technology \& Politics, v. 11, n. 4, p. 412-434, 2014.

SANTANA, R. S. Participação política on-line e off-line nas eleições presidenciais brasileiras de 2014. 2018. 202 f. Tese (Doutorado) - Faculdade de Comunicação, Universidade Federal da Bahia, Salvador, 2018.

SEGESTEN, A. D.; BOSSETTA, M. A typology of political participation online: how citizens used Twitter to mobilize during the 2015 British general elections. Information Communication \& Society, v, 20, n. 11, p. 
$1625-1643,2017$.

SHERMAN, E.; SCHIFFMAN, L. G.; THELEN, S. T. Young Voters' Trust of Information and Media Sources: The 2008 U.S. Presidential Election. Journal of Political Marketing, v. 11, n. 4, p. 246-264, 2012.

ŠTĚTKA, V.; MAZÁK, J. Whither slacktivism? Political engagement and social media use in the 2013 Czech Parliamentary elections. Cyberpsychology: Journal of Psychosocial Research on Cyberspace, v. 8, n. 3, 2014.

STRANDBERG, K. A social media revolution or just a case of history repeating itself? The use of social media in the 2011 Finnish parliamentary elections. New Media \& Society, v. 15, n. 8, p. 1329-1347, 2013.

TANG, G; LEE, F. L. F. Facebook use and political participation: The impact of exposure to shared political information, connections with public political actors, and network structural heterogeneity. Social science computer review, v. 31, n. 6, p. 763-773, 2013.

TAPSCOTT, D. A hora da geração digital: como os jovens que cresceram usando a internet estão mudando tudo, das empresas aos governos. Rio de Janeiro: Agir Negócios, v. 445, 2010.

TOWNER, T. L. All Political Participation Is Socially Networked?: New Media and the 2012 Election. Social Science Computer Review, v. 31, n. 5, p. 527-541, 2013.

SHAH, D.; KWAK, N; HOLBERT, R. L. "Connecting” and "disconnecting" with civic life: patterns of internet use and the production of social capital. Political Communication, v. 18, n. 2, p. 141-162, 2001.

VACCARI, C. Online Mobilization in Comparative Perspective: Digital Appeals and Political Engagement in Germany, Italy, and the United Kingdom. Political Communication, v.34, n. 1, p. 69-88, 2017.

WAGNER, M. When do parties emphasise extreme positions? How strategic incentives for policy differentiation influence issue importance. European Journal of Political Research, v. 51, n. 1, p. 64-88, 2012.

WINCHESTER, T. M.; BINNEY, W; HALL, J. Young adults and politics: investigating factors influencing voter decision making. Journal of Nonprofit \& Public Sector Marketing, v. 26, n. 3, p. 226-257, 2014.

ZUPIC, I; ČATER, T. Bibliometric methods in management and organization. Organizational Research Methods, v. 18 , n. 3, p. 429-472, 2015. 